\title{
Decision-Makers' Perceptions of the Value and Impact of Visual Interactive Modelling
}

\author{
Peter C. Bell, University of Western Ontario \\ Chris K. Anderson, University of Western Ontario \\ D. Sandy Staples, University of Melbourne \\ Mark Elder, University of Strathclyde
}

This article reports results from surveying decision makers who had used a visual, interactive (VI) model to aid their decision making. The survey was a follow-up to an earlier survey of modelers who had built at least one VI model. The model builders reported on their practical experience with VI model building, including their assessment of decision makers' reactions to their models. The present survey was conducted to sample decision makers directly, and the results generally confirm the high level of support and interest in VI models among decision makers.

\section{Introduction}

Visual interactive modelling (VIM) in management science/operational research originated with Hurrion's development of a visual interactive simulation (VIS) model to assist job shop scheduling problems in manufacturing [15]. Commercial VIM software has been available for over a decade beginning with SEE-WHY [20] in 1981, and most commercial simulation software now includes the capability to add animation and interaction to simulation models. VIM is no longer restricted to simulation: visual and interactive examples of dynamic programming, linear programming, integer programming, queueing analysis, and other techniques have appeared $[4,5,8,11,13,17,23,25,26]$. An extensive review of VIM appears in [2].

VIM integrates mathematical or symbolic models with runtime interaction and real-time graphic displays of the model output to aid decision-makers [21]. Several authors [3,9] have discussed a methodology for VIM, and have emphasized that VIM methodology differs fundamentally from traditional management science model-building. In VIM, the interplay between the mathematical or symbolic model and the screen displays (of 'visual model') adds to the importance of user involvement 
in all stages of model development. Several common VIM methodologies $[3,4,10,19,22]$ have much in common with the iterative design, or 'prototyping', approach in which a test-evaluate- improve cycle is repeated until the user's and model builder's understanding of the problem, the visual model, the mathematical or symbolic model which drives the screen images, and the solution, converge [10].

Some of the many claims regarding VIM effectiveness that appear in the literature include:

- Industry adoption of VIM has been managerially driven $[1,21]$.

- The visual display and interactive abilities of visual interactive (VI) models are useful marketing tools for operational research [14, 19, 25].

- Managers find the major benefits of VIM to be in model validation which leads to increased confidence $[1,4,6,12,16]$, in group decision making [18], and in incorporating qualitative dimensions into quantitative models [1].

- An effective VI model assists users in learning about the problems being modelled [7].

- Managers who use VIM get more involved in model building and model use $[4,11]$.

- VIM techniques have improved communications, understanding and insights between the model user and model builder [19].

- The time and effort required to solve a problem is increased (decreased) by the use of VIM $[21,24]$.

These claims are supported primarily by anecdotal evidence or case studies; however, in 1987 Kirkpatrick and Bell [21] carried out a more systematic study by surveying VI model builders. Their study found sup- port for virtually all of the claims listed above, and also helped to clarify the reasons for the conflicting claims regarding the time needed to solve a problem using VIM. The survey data suggested that experienced VI model builders took less time to solve a typical problem using VIM, while novice VI modelers took more time as a result of the set up cost and time associated with learning the new technique.

Kirkpatrick and Bell's survey [21] gathered the views of VI model builders, and included many questions where the model builder was asked to provide the perspective of the manager/enduser/decision maker. Since model builders expressed the view that management was very positive about VIM, it appeared logical to attempt to survey managers to obtain their views directly.

The objective of the current study, therefore, was to investigate what the end-user of VIM (i.e., the decision-maker) thought about the impact of VIM use on their decision making. Issues investigated include: the types of problems where VIM was used; the influences on the decision to use VIM; the impact of VIM on decision making; and the perceived advantages and disadvantages of VIM to decision- 
makers. After describing the methodology used for this study, the findings will be discussed and, where appropriate, compared with the views of VI model builders reported earlier [21]. Finally, some conclusions will be offered.

\section{Methodology}

Survey

A nine-page questionnaire, consisting of both open- ended and Likert scale questions, was developed to probe decision-makers' views of VIM. Identifying a sample of potential respondents proved to be extremely difficult. We tried three methods to reach decision-makers who had actually used VIM for problem solving. First, we mailed questionnaires to all VIM users known to us. Second, we reviewed recent issues of the more application-oriented operational research journals (i.e., Interfaces, European Journal of Operational Research, Journal of the Operational Research Society) for articles describing VIM applications. We mailed questionnaires to the authors of relevant articles requesting them to complete the questionnaire if they were the decision-maker or, if not, to forward the questionnaire to the decision-maker who used VIM as described in the article.

Our third approach to reach decision-makers who had used VIM was to go through software houses that supplied VIM software. We contacted software houses in North America and the United Kingdom that sold VIM packages and requested that they assist us by distributing our questionnaires to their clients. Since their client contacts were usually builders of VI models rather than end-users, we included a request to the model builder to forward the survey onto their client -the decision-maker/enduser. Going through two parties to reach the target respondent greatly increased the probability of nonresponse, and made it impossible for us to know how many end-users actually received our questionnaire. We did send reminder notices but, again, these had to be sent through the software houses and the client model builder. After many months of effort and sending out some three hundred questionnaires, our efforts yielded only 34 usable responses.

The responses are analyzed in a largely descriptive fashion. Where the questions are comparable, unpaired t-tests are used to determine if there are statistically significant differences between the model builders' responses and the decision-makers' responses. In addition, Mann-Whitney $\mathrm{U}$ tests are carried out to test for significant differences between the responses of self- declared managers/decision makers and the other respondents in this study. Only four cases were found where there were statistically significant differences in the answers between the two groups of potential 
decision makers and these are described in the results section below. The similarity in the responses helps build confidence that we reached a population with similar views towards VIM.

\section{Interviews}

In an effort to complement the quantitative data gathered via the survey, telephone interviews were con- ducted with individual decision makers who were using VIM. The interviews focused upon known decision-makers and managers in an effort to address uncertainty in the managerial status of some of the survey respondents. Potential interviewees were initially approached through contacts made at the 1997 Spring INFORMS conference in San Diego. Respondents were identified through attendance at conference presentations where potential interviewees were identified as well as individuals who may have had contact with decision makers using VIM. This selection process is expected to yield a sample biased towards individuals with positive experiences using VIM.

In the interviews a series of questions were asked in an attempt to determine the impact and usefulness of VIM on decision-making by these individuals. Each interview was approximately 10 minutes in duration. Questions focused initially on company background and operations and led into exposure and use of VIM. The nature of the questions was such that respondents were encouraged to provide open-ended opinions on the usefulness of VIM, and of its advantages or disadvantages.

\section{Survey Results}

\section{Characteristics of the Respondents}

The majority of the respondents worked for organizations in the manufacturing sector (23 respondents $-67 \%$ ) which manufactured a wide range of products including: furniture, food products, glass, heavy and electrical equipment, agrochemicals, electronics, fabrics, building products, wood, automotive and steel. Heavy and electrical equipment (4 respondents), auto- motive (3), and steel (3) manufacturing firms were the most numerous. The remaining 11 respondents (33\%) worked in service

industries including the financial, utilities, airlines, and transportation industries. The responses suggest that VIM has achieved broad use across many industries.

Respondents were asked to indicate their functional areas and their job titles. Twelve (36\%) of the respondents worked in a production/operations function, eleven (33\%) in engineering, six (18\%) in research and development, and two (6\%) worked in a consulting function. One respondent each worked in computer services and on a cross-functional team, while one respondent chose not to answer this 
question. The job titles were grouped into five types: operational researcher/systems analyst (11 respondents - 33\%); engineer (10 respondents - 30\%); manager ( 6 respondents $-18 \%)$; coordinator (3 respondents $Ð 9 \%$ ); and consultant (3 respondents - 9\%). In order to investigate differences between those respondents who clearly appeared to be decision-makers and those that may not be, the responses of the managers and coordinators were grouped together and compared to all the other responses.

It was disappointing how few respondents actually held line management positions but we recognize that this was the most difficult group of respondents to reach: we are reluctant to conclude that these small numbers imply that few line managers use VIM.

The respondents' experience with VIM varied. Ten (29\%) of the respondents had been aware of VIM capability in their organization for a year or less, thirteen (38\%) had known about VIM between one and three years, and eleven (33\%) had known about VIM for more than three years. Sixteen (47\%) of the respondents had used only one VI model. Fifteen (44\%) had used two to five VI models, while three (9\%) respondents had used more than five.

The awareness of VIM responses of the managers and coordinators were significantly different from those of the rest of the respondents $(U=53 ; p=0.026)$. The managers and coordinators were aware of VIM 17 months on average while the rest of the respondents had known about VIM an average of 39 months.

\section{Types of Problems Addressed with VIM}

Respondents were given a list of seven task descriptions and asked to rank those that applied to their most recent VIM application. Many respondents chose more than one description (see Table 1). Resource allocation and operational control were among the most frequently mentioned and ranked as first for approximately one-third of the respondents who selected that task. Capital investment and operational control were the most common tasks addressed by VIM in the study of model builders [21].

Respondents were also asked to describe the task in more detail via an open-ended question. These responses were grouped into five categories. A strong majority of respondents were using VIM for production planning/scheduling (22 respondents, 67\%). Five respondents (15\%) used VIM for personnel planning/scheduling. Three (9\%) used VIM for resource al- location. Two (6\%) used VIM for logistical planning and one (3\%) for risk analysis. The study of VI model builders [21] found that the design of manufacturing systems was the most common task where VIM was used. 
We provided five statements that are commonly used to describe why VIM is used. The statements were obtained by searching the literature and correspond to statements used earlier [21]. Respondents were asked to rate the applicability of each statement to their last VIM project (from 1, 'strongly disagree', to 5, 'strongly agree'), and to rank the three dimensions that most influenced their decisions for using VIM. Their responses are summarized in Table 2.

Respondents agreed most strongly with the statements regarding the inability to measure some import- ant dimensions using a meaningful numerical scale and that the decision rules were not static. System complexity was the most frequently cited reason for using VIM, by a fairly large margin. This is consistent with the model builders' views [21]. Having nonstatic decision rules, and trying to find a balance between different objectives were also frequently mentioned as influencing the choice to use VIM.

The two statements where there were significant differences between decision-makers' and model- builders' suggest that model-builders recognize multi dimensionality to a significantly greater extent, while the reverse is true for measurement issues: decision- makers were not as convinced as model-builders that important dimensions of their problems could be meaningfully quantified.

Table 1

From a list of seven task descriptions, respondents ranked those tasks that were part of their most recent VIM application

\begin{tabular}{lllll}
\hline Task description & $\begin{array}{l}\text { Ranked as } \\
\text { 1st (\%) }\end{array}$ & $\begin{array}{l}\text { Ranked as } \\
\text { 2nd (\%) }\end{array}$ & $\begin{array}{l}\text { Ranked as 3rd } \\
\text { or lower (\%) }\end{array}$ & $\begin{array}{l}\text { Number of respondents } \\
\text { who selected that type } \\
\text { of task (n = 34) }\end{array}$ \\
\hline $\begin{array}{l}\text { Long term planning } \\
\text { Resource allocation }\end{array}$ & 22 & 30 & 48 & 23 \\
Operational control & 36 & 32 & 32 & 22 \\
Short term facilities planning & 38 & 24 & 38 & 21 \\
Capital investment decisions & 20 & 25 & 55 & 16 \\
Budgeting & 38 & 19 & 43 & 8 \\
Other & 13 & 38 & 50 & 4 \\
\hline
\end{tabular}

Influence of VIM on the Time Taken for the Decision Process

Respondents were asked to estimate whether the time taken for the entire process (from problem description through to implementation) differed as compared to the time that would have been expected if another technique had been used. If the respondents said the time was longer or shorter, they were asked to provide an estimate of the number of weeks it was longer or shorter. The responses are provided in Table 3. 
The view of the decision-makers regarding the impact of using VIM on the time taken for problem solving is more bullish than that of the model builders: $46 \%$ of the decision-makers feel that the process was shorter versus $27 \%$ of the model builders. However, even though fewer decision-makers thought it took longer, those who did, felt it took an average of several weeks longer than that estimated by the model builders (an average 12 weeks longer estimated by decision- makers versus an average 4.2 weeks estimated by model builders).

Respondents were asked again later in the survey to indicate if more or less time was spent on problem solving when VIM was used. Eighteen (53\%) indicated it took less time; six (18\%) indicated VIM use took the same amount of time; and ten (29\%) respondents indicated it took more time. These results are generally consistent with the earlier responses, discussed above.

Respondents were then asked to identify the stages of the problem-solving process where more or less time was spent (see Table 4). The majority of the respondents (66\%) felt that the same amount of time was spent in problem definition, but that more time (53\% of the respondents indicated this) was spent in model development. Approximately the same number of respondents chose less time or more time for the model validation and analysis stages.

Forty-one percent of the respondents indicated that VIM use resulted in 'implementation' taking less time. Only $6 \%$ indicated that 'implementation' took more time (53\% said it took the same time). Respondents were asked "Does it seem that the implementation of your decisions is easier when a VIM is used?" Thirty- one (94\%) answered yes to this question while only two respondents (6\%) answered negatively. A similar question was asked of model builders [21] except the word 'decisions' was replaced by 'recommendations'. Twenty-one (70\%) model builders felt that the use of VIM did make implementation of their recommendations easier.

\section{Interactions between Model Builders and Decision-Makers}

Respondents were asked when model builders interacted with them (i.e., during the initial problem or system development, during the VI model development, or not at all). Ninety-three percent (25 respondents) of the decision-makers stated that the model builder consulted with them during initial problem or system development and/or during VI model development. This is consistent with the results from model builders [21]. Ninety-seven percent of the model builders said they consulted with the users either during the initial problem or system development and/ or during model development.

A series of questions was asked aimed at identifying the perceived benefits of the interaction between the user and model builder (see Table 5). A large majority of the decision-makers felt that the 
interaction helped the modeler understand the system being modelled better (21\%) or a great deal better $(76 \%)$, and understand the problem better (31\%) or a great deal better (59\%). All decision-makers felt that the interaction resulted in a VIM that was better $(24 \%)$ or a great deal better $(76 \%)$ for the decision-maker. These results are largely consistent with the model builders' views although the decision-makers were the more positive.

Respondents were asked to indicate those components of the $\mathrm{VI}$ model where their input during system development had the greatest impact (see Table 6). With the exception of 'statistical results', a majority of the respondents felt that their input had had a major impact. 'Other' components listed (Table 6) included reports, data collection, databases, and knowledge of tasks. The managers' and coordinators' perceived impact of their input on the logic of the model was significantly less than the rest of the respondents' perceived impact $(U=35 ; p=0.005)$.

Table 2

Five situation descriptions were rated by respondents as applicable to their last VIM project and ranked according to their influence on the decision to use VIM

\begin{tabular}{|c|c|c|c|c|c|}
\hline \multirow[t]{2}{*}{ Statements from questionnaire } & \multicolumn{2}{|l|}{ Rating score } & \multicolumn{3}{|c|}{ Influence on choice of VIM use (frequency) } \\
\hline & $\begin{array}{l}\text { mean; S.D. high } \\
\text { values = agreement }\end{array}$ & $\begin{array}{l}t \text {-test for response of } \\
\text { VIM end-users versus } \\
\text { VI model builders }\end{array}$ & most influence $(\%)$ & second influence $(\%)$ & third influence $(\%)$ \\
\hline $\begin{array}{l}\text { The problem involved a large number of dimensions, } \\
\text { making it more a model of a system than a model to solve } \\
\text { a simple problem }\end{array}$ & $3.13 ; 1.50(4.28 ; 0.92)$ & $4.00^{\circ}$ & $64(58)$ & $36(24)$ & $0(18)$ \\
\hline The decision rules are not static & $4.24 ; 0.79(3.97 ; 0.87)$ & 1.35 & $22(11)$ & $30(33)$ & $48(56)$ \\
\hline $\begin{array}{l}\text { The problem entailed finding a best balance between } \\
\text { different objectives }\end{array}$ & $3.85 ; 1.20(4.08 ; 0.70)$ & 1.00 & $17(18)$ & $39(36)$ & $44(46)$ \\
\hline $\begin{array}{l}\text { Some important dimensions of the problem could not be } \\
\text { measured using a meaningful numerical scale }\end{array}$ & $4.63 ; 0.66(3.41 ; 1.19)$ & $5.17^{*}$ & $46(53)$ & $8(7)$ & $46(40)$ \\
\hline A group would be responsible for choosing the solution & $3.75 ; 1.11(3.87 ; 0.83)$ & 0.53 & $0(6)$ & $57(63)$ & $43(31)$ \\
\hline
\end{tabular}

${ }^{*} p<0.05$. Values in parentheses are from the survey of model builders [21].

\section{The Influence of VIM on the Decision Made}

Respondents were asked if they thought a different solution was arrived at because VIM was the method used for analysis. Sixty-two percent (21 respondents) of the decision-makers replied in the affirmative. This is consistent with [21] in which $65 \%$ of model builders agreed that a different solution was arrived at due to the use of VIM.

Respondents were also asked if they thought a different definition of the problem or system emerged during VIM development. Fifty-three percent (18) of the decision-makers thought that a different definition of the problem did emerge during VIM development which is, again, fairly consistent with the study of model builders (62\% agreed with the same question [21]). 
Respondents were asked to estimate how they spent their time using the VI model, which was divided into five activities, including an open-ended 'other' category (Table 7). Entering data was reported to take the most time followed by waiting for answers. The tasks listed under 'other' included: reviewing input data and rules; changing the design; interpreting output from model; printer and further processing results; viewing/analyzing final results; testing 'what if' scenarios; manipulating jobs on a planning board; and iteration with customers and subsequent amendment of models. The managers' and coordinators' spent significantly less time watching animations than the rest of the respondents ( $U$ $=42 ; p=0.007)$.

Table 3

Time taken for problem solving with VIM versus some other technique

\begin{tabular}{|c|c|c|c|}
\hline & Shorter & Same & Longer \\
\hline Frequency chosen & $\begin{array}{l}13(46 \%) \\
10(27 \%)\end{array}$ & $\begin{array}{l}5(18 \%) \\
9(24 \%)\end{array}$ & $\begin{array}{l}10(36 \%) \\
18(49 \%)\end{array}$ \\
\hline $\begin{array}{l}\text { Mean response; standard deviation (in weeks) } \\
\text { Range of responses }\end{array}$ & $\begin{array}{l}9.8 ; 9.9(6.4 ; 7.1) \\
<5 \text { weeks: } 6 \\
5-20 \text { weeks: } 5 \\
20-30 \text { weeks: } 2\end{array}$ & & $\begin{array}{l}12.0 ; 15.4(4.2 ; 7.4) \\
<5 \text { weeks: } 5 \\
5-14 \text { weeks: } 3 \\
22 \text { weeks: } 1 \\
52 \text { weeks: } 1\end{array}$ \\
\hline
\end{tabular}

Values in parentheses are from the survey of model builders [21].

Table 4

Respondents were asked to indicate if using VIM took more, less or the same time for five stages of problem-solving

\begin{tabular}{lrrr}
\hline Problem-solving stage & Less time & Same time & More time \\
\hline Problem definition & $7(22 \%)$ & $21(66 \%)$ & $4(12 \%)$ \\
Model development & $9(28 \%)$ & $6(19 \%)$ & $17(53 \%)$ \\
Model validation & $15(47 \%)$ & $3(9 \%)$ & $14(44 \%)$ \\
Analysis & $14(42 \%)$ & $6(18 \%)$ & $13(40 \%)$ \\
Implementation & $13(41 \%)$ & $17(53 \%)$ & $2(6 \%)$ \\
\hline
\end{tabular}

Table 5

The impact of builder/user interaction

\begin{tabular}{llll}
\hline Statements from questionnaire & No better & Better & A great deal better \\
\hline $\begin{array}{l}\text { Do you feel that this interaction helped } \\
\text { the model builder to understand the }\end{array}$ & $\begin{array}{l}1 \text { respondent; } 3 \% \\
(3 ; 9 \%)\end{array}$ & $\begin{array}{l}6 \text { respondents; } 21 \% \\
(12 ; 35 \%)\end{array}$ & $\begin{array}{l}22 \text { respondents; } 76 \% \\
(19 ; 56 \%)\end{array}$ \\
$\begin{array}{l}\text { system being modelled? } \\
\text { Do you feel that this interaction helped } \\
\text { the model builder to understand the } \\
\text { problem }\end{array}$ & $3 ; 10 \%(5 ; 15 \%)$ & $9 ; 31 \%(14 ; 41 \%)$ & $17 ; 59 \%(15 ; 44 \%)$ \\
$\begin{array}{l}\text { Do you feel that this interaction resulted } \\
\text { in a VIM that was better for the } \\
\text { decision-maker }\end{array}$ & $0(1 ; 3 \%)$ & $7 ; 24 \%(15 ; 44 \%)$ & $22 ; 76 \%(18 ; 53 \%)$ \\
\hline
\end{tabular}

Values in parentheses are from the survey of model builders [21]. 
Table 6

The impact of the decision-maker's input during system development

\begin{tabular}{lccc}
\hline Components of the system & No impact & Little or some impact & Major impact \\
\hline Pictures/graphics displays & 4 respondents $(13 \%)$ & 11 respondents $(35 \%)$ & 16 respondents $(52 \%)$ \\
Interactions & $1(3 \%)$ & $10(33 \%)$ & $19(64 \%)$ \\
Logic of the model & $2(6 \%)$ & $9(29 \%)$ & $20(65 \%)$ \\
Statistical results & $1(3 \%)$ & $15(52 \%)$ & $13(45 \%)$ \\
Other & $1(13 \%)$ & $2(25 \%)$ & $5(62 \%)$ \\
\hline
\end{tabular}

Table 7

How did the users spend their time using the VI model?

\begin{tabular}{|c|c|c|c|c|c|}
\hline How did users spend their time with the VI model & $0 \%$ & $1-25 \%$ & $26-69 \%$ & $\geq 70 \%$ & mean $(\%)$; standard deviation \\
\hline Entering data & 3 & 12 & 13 & 6 & $33.4 ; 26.1$ \\
\hline Asking the system questions & 8 & 23 & 2 & 1 & $13.0 ; 14.2$ \\
\hline Waiting for answers & 3 & 17 & 10 & 4 & $29.4 ; 27.7$ \\
\hline
\end{tabular}

Benefits of VIM

Respondents were asked in an open-end question to list the benefits of VIM. The responses were analyzed and grouped into five categories. The most frequently mentioned aspect (18 responses) was the visual/graphic display. A greater understanding of complex problems for groups, and the ability to make changes relatively fast were both mentioned seven times each. The ability to interact with the model, and the ability to ask 'what if' questions were mentioned twice each.

The respondents were also asked to list the major benefits of VIM to them. In the responses (Table 8), making the decision easier to sell to others was mentioned by $29 \%$ of the decision-makers. This may be comparable to the benefit listed by $30 \%$ of the model builders that the results of the decision are clear. Increased confidence in the results was mentioned by $22 \%$ of the decision-makers and $51 \%$ of the model builders. Ease of model use and experimentation was mentioned by $20 \%$ of the decision-makers and $11 \%$ of the model builders (quick and easy experimentation). 
Table 8

The major benefits of VIM to decision makers

\begin{tabular}{lr}
\hline & Frequency \\
\hline $\begin{array}{l}\text { Major benefits of VIM to decision-makers (responses from } \\
\text { decision-makers) }\end{array}$ & $12(29 \%)$ \\
Decision easier to sell to others & $9(22 \%)$ \\
Increased confidence in results & $8(20 \%)$ \\
Ease of model use and experimentation & $7(17 \%)$ \\
Speed of model building & $5(12 \%)$ \\
Speed of decision-making process & $3(7 \%)$ \\
Clearer problem definition & \\
& \\
Major advantages of VIM to decision-makers (responses from \\
model builders [21]) & \\
Increased confidence in model & $19(51 \%)$ \\
Results of decisions clear & $14(38 \%)$ \\
Helps to clarify problem & $8(22 \%)$ \\
Quick and easy experimentation & $4(11 \%)$ \\
Increased involvement in process & $3(8 \%)$ \\
Group commitment increased & $3(8 \%)$ \\
Increased control & $3(8 \%)$ \\
\hline
\end{tabular}

\section{Disadvantages of VIM}

Respondents were asked an open-ended question regarding what they saw as the major disadvantages of VIM. In the responses (Table 9) approximately one- third of the decision-makers listed development time and the expertise required as a disadvantage of using VIM. While model builders did not specifically mention these disadvantages, they did mention long lead times (9\%), and software difficulties and restrictions (26\%) as disadvantages which may be comparable to the long development time seen by the decision- makers. Fifteen percent of the decision-makers' (and $14 \%$ of the model builders') mentioned the acceptance of results without full understanding of the model or its assumptions as a disadvantage of VIM. A similar issue, getting out of touch with assumptions, was also mentioned by $9 \%$ of the model builders as a VIM dis-advantage. Fewer decision-makers ( 1 response= 4\%) listed increased time required of the decision-maker in the process as a disadvantage compared to the model builders (5 responses $=14 \%$ ). Most of the other disadvantages listed dealt with technical problems with VIM (e.g., lack of networking capability, running speed).

\section{Interview Results}

Following the survey, we conducted five open-ended interviews by telephone with managers and decision makers who had used VIM in their decision making. While VIM has the potential to be used 
with various techniques (e.g. $[5,17,26])$ current practice usually finds it being used with simulation models. The five interviews below reflect this practice as the participants discuss their use of VIS.

Table 9

The major disadvantages of VIM to decision makers

\begin{tabular}{lr}
\hline & Frequency \\
\hline $\begin{array}{l}\text { Major disadvantages of VIM to decision-makers (responses } \\
\text { from decision-makers) }\end{array}$ & $9(34 \%)$ \\
$\begin{array}{l}\text { Development time and expertise required } \\
\text { Acceptance of results/model without full }\end{array}$ & $4(15 \%)$ \\
understanding & $4(15 \%)$ \\
No ability to network or deal with multi-users & $3(12 \%)$ \\
Slow running speed of the model & $2(8 \%)$ \\
Limited access to VIM system equipment & $2(8 \%)$ \\
Limited ability to model the 'Real World' & $1(4 \%)$ \\
Convincing other people of its benefits & $1(4 \%)$ \\
More time required of the decision-maker in the & \\
process & \\
& \\
Major disadvantages of VIM to decision-makers (responses \\
from model builders [21])
\end{tabular}

Jackie Hueter, Manager Restaurant Systems Engineering, Taco Bell Corporation.

Taco Bell (TB) has been using simulation as a decision tool since the mid 1980's. Simulation is used in a variety of roles and has been found to be an extremely valuable tool. Simulation is used in solving problems regarding direct labor, speed of service, new product issues, as well as new equipment purchases. Simulation allows the representation of difficult aspects and allows the addition of some randomness, which might not otherwise be included. Modelling is done both internally and externally, with smaller jobs involving limited programming done internally, and larger jobs handled through external consultants. Jackie is generally involved in all efforts to some degree, whether it be initiating the effort or reviewing/interpreting the external work. Live mock-ups are some- times performed alongside simulation models in an effort to provide additional information, as well as for validation and refinement of existing models.

Jackie and TB have found animation to be a welcome addition to simulation. TB is a high turnover corporation and animation has expedited the acceptance of simulation. Animation is deemed useful in many steps of the process, from initial visual validation of what is going on (queues, bottlenecks, etc.), to helping those less familiar with simulation to understand the technique and the results (restaurant managers and the senior teams). 
TB relies on the graphics to transmit the messages to less technical personnel, allowing all to become involved, generating interest and to some degree increasing the validity of the model (as seen by senior personnel). Success of future efforts will be influenced by animation and graphics as TB hopes to introduce simple models at the restaurant level to aid store man- agers in the day-to-day operations. TB has introduced a highly graphic, interactive, work-force scheduling system in some 4000 restaurants. This system was developed using mixed-integer programming and simulation model results and enables restaurant managers to match workforce levels and schedules to traffic intensities. Jackie looks to graphical presentations to facilitate the transmission of ideas and the inclusion of more dimensions as TB expands internationally.

Janice Li, Senior Industrial Engineer, AMTRAK.

Janice is a senior engineer with AMTRAK using simulation primarily for long term planning. AMTRAK has been using simulation for approximately three years, with most of their energy focused on repeated use of a single model. Simulation was initially looked upon as a new alternative for problem solving, hypothesis testing and long term planning, and the acceptance of simulation to solve problems within AMTRAK is attributed to the graphical inter- face and animation capability. The benefit of being able to present an overall picture and bringing all the critical functions into the model has been a strong selling point in decision making. As a result, simulation is becoming a useful communication tool, in addition to a valuable system planning tool.

Joel Hoffner, Principal, E and E Corporation.

$\mathrm{E}$ and $\mathrm{E}$ is a consulting company to the steel industry, working primarily with steel manufacturing operations. Joel has been working with simulation models for approximately 20 years. While no longer actually programming the models, Joel works with the modeler and the customer to develop the model logic. Joel then later debugs the model and works extensively with the client to perform simulations and test scenarios and get a feel for operational changes.

From Joel's standpoint, as well as that of E and E's clients, the recent developments in animation and the quality of graphical displays are absolutely essential. The animation greatly facilitates model debugging and determination of logic flaws. From the clients view- point the graphics facilitate an understanding of the model and make the results believable. Facility changes and adjustments are better understood if able to be visualized.

Doug Shannon, Senior Engineer, TRW.

Performance simulation has been used as a tool for several years (10+) with animation playing a role in the last three years. Simulation serves in a variety of roles with a primary focus on data process 
and flow as well as throughput. Generally simulation serves to decrease the length of the decision process as it becomes a forcing function which creates questions and brings forth the postulating of questions/decisions which normally would not be addressed in the early decision steps. The designer is forced to address problems earlier.

Often the driving force for simulation is the customer. The best asset you can have is a good customer; one who understands the value of simulation and one who can fully appreciate and use the results. Inclusion of simulation is often driven by the client with their actual statement of requirement in the proposal process.

Typically simulation is very helpful. The only visible disadvantages of simulation center around the overselling of the results. While results may be $90 \%$ golden they are often sold as $100 \%$ golden without any question. The major advantage of simulation centers around cost effectiveness. When a simulation indicates problems, nine times out of ten the problem is within the model, but one time out of ten the problem is in the design. It is this one time in ten that creates the largest cost benefit, as problems originate (and can be resolved) prior to implementation.

Final impressions: simulation moves decision analysis earlier into the life cycle; secondary decisions must be addressed with the primary decision. Overselling of simulation is a concern while its practice is fruitful; guilt driven by over-reliance is a concern. Lastly animation, while offering little technical advantage, draws in the customers, and increases their input and acceptance.

Gregg Blankenship, Director Manufacturing Technology, Cymer Laser Technologies.

Cymer is currently using the fifth generation of a year old PROMODEL simulation. The initial model logic was developed internally with programming occurring externally by a consultant, and since has been continually modified and used internally.

Cymer uses the model as a risk reduction tool for planning and manufacturing. The model is just starting to be used as a management tool, as very few people understand the model or why it would be used. Credibility through validation has facilitated model acceptance.

Management finds little use for the graphical nature or animation of the model. While initially useful to ensure logic was properly programmed, subsequent model use focuses upon tabular spreadsheet output, more traditional production, and 'scheduling type' tables.

\section{Limitations of the Research}

The samples used in the current study and Kirkpatrick and Bell's study [21] were not randomly selected. In both cases, an attempt was made to reach as many users of VIM as possible. Since software 
houses were used as the distributing mechanism for many of the questionnaires, selection of the potential survey respondents was outside the authors' control.

From reviewing the job titles of the respondents, it is clear that not all of the respondents were decision- makers/managers who were distinctly separate from the model builders. One-third of the sample were operational researchers/systems analysts who were likely performing as decision makers while closely involved in the model building efforts. We may not, therefore, have obtained a clear picture of the reaction of the line manager to VIM.

We have implied that differences in the responses of model builders and decision-makers are due to their different functions and focus. However, the differences could also result from changes in VIM technology over the time period between the two studies, or from different applications where VIM was used, or be due to other circumstances. We made no attempt to control for other factors or to match the model builders and decision-makers.

\section{Discussion}

The current study has added to our understanding of VIM. Kirkpatrick and Bell [21] concluded from their study that model builders had a 'bullish' view of VIM. The results of the survey and telephone inter- views suggest that decision-makers have an even more positive view of VIM than do model builders, which explains the strong acceptance of VIM in the market- place. Decision makers who have been exposed to VIM generally view this experience positively.

The results from the survey provide empirical support for several of the conjectures from the literature.

The common perception that VIM leads to enhanced communication between modelers and decision-makers is supported. Ninety-three percent of the survey respondents stated that the model builders did consult with them either during the initial problem development and/or during VIM development. All the decision-makers felt that this interaction resulted in a VIM that was better for them to use. The majority of the survey respondents also felt that their input had an impact on the components of the systems, implying that they felt the model builders listened to them.

The results lend support to the proposition that VIM use assists users to learn about the problem being modelled. Slightly over half the survey respondents felt that a different definition of the problem emerged during the development of the VIM, while just under two-thirds felt that a different solution was arrived at because VIM was used. 
Increased confidence in the results, and making the decision easier to sell to others were the two most frequently mentioned benefits of VIM, lending support to the common perceptions that VIM enhances model validation and user confidence, as well as being a good marketing tool for operational research.

About half the decision-makers felt that the decision making process took less time when VIM was used; however, a substantial proportion (about one-third) felt it took longer. When survey respondents were asked to break the decision process into five stages and estimate whether the stages were longer or shorter with VIM, a striking result was observed regarding the implementation stage. Only $6 \%$ of the respondents felt implementation took longer using VIM: $41 \%$ felt that it took less time. This, coupled with the high degree of agreement (94\%) that implementation is easier with VIM, may partially explain why decision-makers are very positive about VIM use. As decision-makers, the responsibility for implementation would rest with them so reducing the time to implement their decisions would be very valuable.

The interviews add qualitative support to the survey data. The interviews with Hueter, Li, Shannon and Hoffner support the survey results of Table 8. The interviewees indicated that visualization and inter- action positively impact the acceptance of the results, similarly over half of survey respondents selected Decision is easier to sell or Increased confidence in results as major benefits of VIM.

Similarly, Hueter and Li portrayed visualization and interaction as a useful communication tool for the users and model builders, reinforcing the results of Table 5 which indicated that the interaction between model builder and decision maker was beneficial with VIM effectively becoming a communication tool between them ( $93 \%$ of the survey respondents said interaction did occur).

Three of the interviews, those with Hueter, Hoffner and Blankenship, indicated that visualization and interaction enhances the model validation process. While Table 4 of the survey results illustrates that VIM did not consistently reduce the time taken for the model validation process ( $47 \%$ said it took less time, $44 \%$ said it took more time) the enhancements added by visualization are not perceived as time oriented but rather, as in Table 8, confidence oriented. The survey data of Table 8, where increased confidence in results ( $22 \%$ of respondents) was viewed as a major benefit and increased confidence in model was viewed as a major advantage ( $57 \%$ of respondents), concurs with the comments of those interviewed.

The similarity of responses from the interviewees to those of the survey respondents provides some support for a view that the survey respondents really were responding as managers and decision- 
makers. The interviews focused upon individuals who utilized VIM as a decision support tool, and whose primary focus was not that of model builder.

\section{Conclusions}

A study of decision makers who had used VIM was undertaken in an attempt to provide empirical support for some of the many conjectures about VIM which appear in the literature.

Overall, the decision-makers' view of VIM is quite positive. This is consistent with the VI model builders' view [21] and is consistent with common perceptions of VIM. Although it is difficult to estimate how many VI models have been developed to date, the positive perceptions of both the end-users and model builders support the high level of activity in today's VIM marketplace.

\section{Acknowledgements}

The authors acknowledge financial support from the Natural Sciences and Engineering Research Council of Canada. We are also grateful to the many software houses and individuals who helped with the distribution of this survey, and to Sulaiman Al-Hudhaif who assisted with survey distribution.

\section{References}

[1] Bell PC. Visual interactive modeling as an operations research technique. Interfaces 1985;15(4):2633.

[2] Bell PC. Visual interactive modelling: the past, the present and the prospects. European Journal of Operational Research 1986; 54(3):274-86.

[3] Bell PC. Visual Interactive Modelling: The Methodological Issues. In: Rand, G, editor. Operational Research '87, Amsterdam: North-Holland, 1988. pp. 97-110.

[4] Bell PC, Parker DC. Developing a visual interactive model for corporate cash management. Journal of the Operational Research Society 1985; 36(9):779-86.

[5] Bell PC, Hay G, Liang Y. A visual interactive decision support system for workforce (nurse) scheduling. INFOR 1986; 24(2):134-45.

[6] Bell PC, Parker DC, Kirkpatrick P. Visual interactive problem solving $Đ$ a new look at management problems. Business Quarterly 1984; 49(1):14-18.

[7] Belton V, Elder M. Editorial of the special issue: visual interactive modelling. European Journal of Operational Research 1991; 54(3):273. 
[8] Bhatnagar SC. Locating social service centers using interactive graphics. Omega The International Journal of Management Science 1983; 11(2):201-5.

[9] Bowen, HC, Fenton, RJ, Rogers, MA, Hurrion, RD, Secker, RJR. Interactive Computing as an Aid to Decision-makers. In: Haley, KB, editor. Operational Research '78, Amsterdam: North-Holland, 1979. pp. 829-842.

[10] Chau Y, Bell PC. Designing effective simulation-based decision support systems: an empirical assessment of three types of decision support systems. Journal of the Operational Research Society $1995 ; 46(3): 315-31$.

[11] Everett, P. Operational Research in the British Airports Authority, presented at the IFORS Conference. Washington, DC, 1984.

[12] Fiddy E, Bright JG, Hurrion RD. SEE-WHY: interactive simulation on the screen. Proceedings of the Institute of Mechanical Engineers 1981; C293(81):167-72.

[13] Garbini JL, Lembersky MR, Chi UH, Hehnen MT. Merchandiser design using simulation with graphical animation. Forest Products Journal 1984; 34(4):61-8.

[14] Hollocks B. Simulation and the micro. Journal of the Operational Research Society 1983;

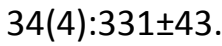

[15] Hurrion, RD. The design, use and required facilities of an interactive visual computer language to explore production planning problem. Unpubl. Ph.D. thesis, University of London, London, 1976.

[16] Hurrion RD. An interactive visual simulation system for industrial management. European Journal of Operational Research 1980; 5(4):86-93.

[17] Hurrion RD. Visual interactive (computer) solutions for the travelling salesman problem. Journal of the Operational Research Society 1980; 31:537-9.

[18] Hurrion RD. Implementation of a visual interactive consensus decision support system. European Journal of Operations Research 1985; 20:138-44.

[19] Hurrion RD. Visual interactive modelling. European Journal Research 1986; 23(3A):281-7.

[20] Istel Limited. SEE-WHY Software. Highfield House, Headless Cross Drive, Redditch, B98 5EU, UK.

[21] Kirkpatrick PF, Bell PC. Visual interactive modeling in industry: results from a survey of visual interactive model builders. Interfaces 1989; 19(5):71-9.

[22] Kirkpatrick PF, Bell PC. Simulation modelling: a comparison of visual interactive and traditional approaches. European Journal of Operational Research 1989; 39(2):138-49.

[23] Lembersky MR, Chi UH. Decision simulators speed implementation and improve operations. Interfaces 1984; 14(4):1-15. 
[24] Melamed A, Morris RJT. Visual simulation: the performance analysis workstation. Computer 1985; 18(8):87-94.

[25] Patel NR. Locating rural social service centers in India. Management Science 1979; 25(1):22 \pm 30 .

[26] Taseen AA. Visual interactive liner programming: the concept, an example and an empirical assessment of its value in supporting managerial decision-making. Unpubl. Ph.D. thesis, The University of Western Ontario, London, Ont., 1993. 